\title{
RAPDS NA CARACTERIZAÇÃO GENÉTICO-MOLECULAR E NO ESTUDO DA VARIABILIDADE GENÉTICA DE CULTIVARES DE AMEIXEIRA ${ }^{1}$
}

\author{
VALMOR JOÃO BIANCHI ${ }^{2}$, JOSÉ CARLOS FACHINELLO ${ }^{3}$; MÁRCIA WULFF SCHUCH ${ }^{4}$
}

\begin{abstract}
RESUMO - Marcadores moleculares têm sido amplamente utilizados nas mais variadas espécies frutíferas para análise de "fingerprinting", para o processo de certificação de material vegetal e como ferramenta auxiliar em programas de melhoramento genético, para acessar a variabilidade genética entre genótipos. Dado a importância da cultura da ameixeira para a região Sul do Brasil, o presente trabalho teve por finalidade contribuir para a caracterização genético-molecular de 17 cultivares. As cultivares foram analisadas com 12 marcadores RAPD, que produziram 187 polimorfismos. O marcador OP A20 foi o mais polimórfico, produzindo 26 perfis diferentes. A análise de agrupamento, realizada com o método UPGMA, produziu um dendrograma que permitiu uma clara separação das cultivares em três grupos, correspondentes às suas respectivas espécies, Prunus salicina, Prunus domestica e Prunus cerasifera. O alto grau de polimorfismo detectado pelos marcadores RAPD confirma o potencial da técnica na análise de "fingerprinting" e sua utilidade na estimativa da variabilidade genética entre cultivares de ameixeira.
\end{abstract}

Termos para indexação: Prunus spp., marcadores moleculares, "fingerprinting".

\section{RAPDS ON GENETIC-MOLECULAR CHARACTERIZATION AND GENETIC VARIABILITY STUDY OF PLUMS}

ABSTRACT - Molecular markers have been used thoroughly in many fruit crops species for fingerprinting analysis during the vegetal material certification process, and as an auxiliary tool in breeding programs to access genetic variability among genotypes. The plum is an important crop in Southern Brazil. The present paper aims to contribute for the genetic-molecular characterization of 17 plum cultivars, which were analyzed with 12 RAPD markers that produced 187 polymorphisms. The OPA20 marker was the most polymorphic, producing 26 different profiles. The cluster analysis was represented by a dendrogram using the UPGMA method, and showed a clear cultivar separation in to three groups corresponding to the species, Prunus salicina, Prunus domestica and Prunus cerasifera, respectively. A high degree of polymorphism was detected by the RAPD markers in the plum. This confirms the potential of the techanique of fingerprinting analysis and its usefulness in the estimate of the genetic variability among plum cultivars.

Index terms: Prunus spp., molecular markers, fingerprinting.

\section{INTRODUÇÃO}

O sucesso no cultivo de plantas frutíferas depende muito da qualidade do material viveirístico, por isso, garantias de correspondência genético-sanitárias são fundamentais devido ao alto investimento de tempo e dinheiro requeridos para implantar um pomar. Segundo Ortiz et al. (1997), a propagação de plantas frutíferas realizada de forma não controlada tem conduzido a perda da identidade de inúmeros genótipos. A correta identificação varietal e o conhecimento da variabilidade genética em espécies frutíferas são importantes para programas de melhoramento genético e para comercialização.

De acordo com Goulão et al. (2001), existe pouco conhecimento sobre a variabilidade genética das cultivares de Prunus salicina (Lindl.), incluindo seleções recentes e seus híbridos envolvendo várias outras espécies (P. armeniaca, $P$. munsoniana e outros) e também sobre o número de genitores utilizados em programas de melhoramento. Devido ao fato de muitas cultivares de ameixeiras serem auto-incompatíveis e híbridos naturais, Shimada et al. (1999) citam que estas características dificultam a verificação da pureza da espécie bem como a classificação de algumas cultivares.

Até pouco tempo, a identificação varietal era baseada na avaliação das características morfo-fenológicas e pomológicas (Sansavini, 1998), porém, este tipo de análise apresenta várias limitações como: requer muito tempo para ser completada, não permite acessar todo o genoma da planta, deixa várias dúvidas quando se trata de genótipos com características muito similares, como verificado em pessegueiro e não pode ser realizada em qualquer período do ano ou ciclo da planta.

Em alternativa, novas metodologias foram introduzidas para a análise genética de plantas. Inicialmente tem sido feito o uso de isoenzimas (Byrne \& Littleton, 1988) e, posteriormente, RAPD (Random Amplified
Polimorphic DNA) têm sido utilizados na elaboração de "fingerprintings" em espécies que apresentam grande variabilidade genética, como ameixeira, pereira e macieira (Mulcahy et al., 1993; Cassas et al., 1999; MonteCorvo et al., 2000).

Entre as várias espécies do gênero Prunus, a ameixeira é aquela que apresenta a maior variabilidade. Em trabalhos realizados por Gregor et al. (1994), Grando \& Vindimian (1996), Ortiz et al. (1997), Bellini et al. (1998) e Shimada et al. (1999), RAPDs produziram suficiente polimorfismo para estudos de filogenia e na análise "fingerprinting" de cultivares de ameixeira. Na análise de 17 cultivares de ameixeira dos gêneros $P$. domestica e $P$. salicina, com 67 "primers" RAPD, Pancaldi et al. (2000) verificaram que a técnica foi capaz de diferenciar 15 cultivares, porém não diferenciou as cultivares de P. domestica, Empress e Grossa di Felisio.

Para contribuir na caracterização de cultivares de ameixeira de maior difusão na Região Sul do Brasil, no presente trabalho buscou-se testar os limites e potencialidades da técnica RAPD na análise "fingerprinting" e na estimativa da variabilidade genética de 17 cultivares de ameixeira.

\section{MATERIAL E MÉTODOS}

O experimento foi conduzido no Laboratório de Cultura de Tecidos do Departamento de Botânica, Instituto de Biologia da Universidade Federal de Pelotas - UFPel, Pelotas - RS, no período de outubro de 2001 a abril de 2002.

O material vegetal utilizado para as análises foram cultivares de ameixeira japonesa (Prunus salicina Lindl.), cultivares de ameixeira européia (Prunus domestica L.) e a cultivar Mirabolano 29C (Prunus cerasifera Ehrh.), conforme consta na Tabela 1. Obteve-se o DNA de $70 \mathrm{mg}$ de folhas liofilizadas e a extração realizada conforme metodologia descrita por

\footnotetext{
${ }^{1}$ (Trabalho 119/2002). Recebido: 08/08/2002. Aceito para publicação: 13/06/2003. Parte da tese apresentada ao Curso de Pós-Graduação em Agronomia, Faculdade de Agronômia Eliseu Maciel, Universidade Federal de Pelotas, pelo primeiro autor, como requisito para obtenção do título de Doutor em Ciência. Trabalho desenvolvido com apoio financeiro do CNPq e Fapergs.

${ }^{2}$ Eng $^{\circ}$. Agr ${ }^{\circ}$. M. Sc., Bolsista do CNPq, Doutorando do CPGA-FAEM-UFPel, Campus Universitário, Fone: (53) 2757124, CP. 354, CEP 96010-900, Pelotas-RSBrasil.E-mail: valmorjb@yahoo.com - Autor para correspondência.

${ }^{3}$ Eng $^{\circ}$. Agr ${ }^{\circ}$., Dr., Prof. Titular Depart. Fitotecnia, FAEM-UFPel, (53) 2757124, C.P. 354, 96010-900, Pelotas-RS-Brasil.

${ }^{4}$ Eng $^{\circ}$. Agr ${ }^{\circ}$., Dra., Prof. Adjunto Depart. Fitotecnia, FAEM-UFPel, (53) 2757124, C.P. 354, 96010-900, Pelotas-RS-Brasil.
} 
TABELA 1 - Variedades utilizadas para estudo de "fingerprinting" e de variabilidade genética. FAEM-UFPel, Pelotas-RS, 2002.

\begin{tabular}{|c|c|c|c|c|}
\hline Código & Variedade & Grupo & Espécie & Fonte do material \\
\hline 1 & Santa Rosa & Japonês & Prunus salicina & $A^{*}$ \\
\hline 2 & Leticia & Japonês & Prunus salicina & $\mathrm{B}$ \\
\hline 3 & América & Japonês & Prunus salicina & $\mathrm{B}$ \\
\hline 4 & Santa Rita & Japonês & Prunus salicina & $\mathrm{B}$ \\
\hline 5 & Pluma 7 & Japonês & Prunus salicina & $\mathrm{B}$ \\
\hline 6 & Reubennel & Japonês & Prunus salicina & $\mathrm{B}$ \\
\hline 7 & Frontier & Japonês & Prunus salicina & $\mathrm{C}$ \\
\hline 8 & The First & Japonês & Prunus salicina & C \\
\hline 9 & Rosa Mineira & Japonês & Prunus salicina & $\mathrm{C}$ \\
\hline 10 & Wade & Japonês & Prunus salicina & C \\
\hline 11 & Iratí & Japonês & Prunus salicina & C \\
\hline 12 & Amarelinha & Japonês & Prunus salicina & C \\
\hline 13 & Ozark Premier & Japonês & Prunus salicina & C \\
\hline 14 & Stanley & Europeu & Prunus domestica & C \\
\hline 15 & D'Agen & Europeu & Prunus domestica & $\mathrm{C}$ \\
\hline 16 & Magnifique & Europeu & Prunus domestica & C \\
\hline 17 & Mirabolano $29 \mathrm{C}$ & Mirabolano & Prunus cerasifera & A \\
\hline
\end{tabular}

* A - FAEM - Universidade Federal de Pelotas, RS - Brasil; B - Viveiro Quinta Marli, Pelotas, RS - Brasil; C - Embrapa Clima Temperado, Pelotas, RS - Brasil.

Mulcahy et al. (1993), com modificações descritas por Bianchi et al. (2002). Após tratamento com RNAse, o DNA foi quantificado e diluído em água estéril para concentração final de $15 \mathrm{ng} \cdot \mu \mathrm{L}^{-1}$, para utilização na reação de polimerização em cadeia (PCR).

Para as amplificações utilizou-se um total de 17 "primers" decâmeros dos kits da Operon - OP(OPA01, OPA07, OPA15, OPA17, OP A18, OP A20, OP AC19, OP AC20, OP AD16, OP AF15, OP AN19, OP AN20, OP B01, OP B19 e OP B20) e da British Columbia University - UBC (UBC 407 e UBC 412). As reações de amplificação foram realizadas em um aparelho termociclador MJ PTC-100, utilizando o perfil térmico conforme Koller et al. (1993). O volume total da mistura de reação foi de $25 \mu \mathrm{L}$, contendo: 2,5 $\mu$ L Tampão 10X (10 mM Tris-HCl pH 9,0,50 mM KCl, 1,5 mM $\mathrm{MgCl}_{2}$ ), 3,75 mM de cada dNTP, $10 \mu \mathrm{M}$ de cada primer, 1 Unidade de Taq polimerase (Invitrogen) e 30 ng de DNA genômico, conforme descrito por Pancaldi et al. (2000).

Os produtos da amplificação foram submetidos à eletroforese em gel de agarose $1,2 \%$; a coloração feita com brometo de etídeo e as bandas visualizadas em luz ultravioleta. As reações de amplificação foram repetidas três vezes para cada "primer" e indivíduo, e para a análise somente foram considerados os dados dos "primers" que produziram bandas que se repetiram em todas as amplificações.

Os perfis eletroforéticos obtidos sobre o gel foram utilizados para a direta diferenciação entre genótipos e para a construção de uma matriz de similaridade genética, que foi elaborada com os dados produzidos por cada "primer", registrando-se a presença (1) e ausência (0) de bandas no perfil eletroforético para cada um dos genótipos. A similaridade genética foi calculada usando o coeficiente DICE GS $(\mathrm{ij})=2 \mathrm{a} / 2 \mathrm{a}+\mathrm{b}+\mathrm{c}$, onde $\mathrm{a}=$ número de bandas polimórficas condivididas; $\mathrm{b}=$ número de bandas em i e c = número de bandas em j) com "software" NTSYS.pc versão 1.8 (Rohlf, 1993). Realizou-se análise de agrupamento para construir um dendrograma de similaridade, empregando o método UPGMA (Unweighted pair group mean average), de acordo com os dados obtidos com os marcadores RAPD.

\section{RESULTADOSEDISCUSSÃO}

Dos 17 "primers" RAPD testados foram utilizados somente os produtos amplificados de 12 "primers" (OPA01, OPA07, OPA15, OPA17, OPA18, OPA20, OPAC19, OPAD16, OPAN19, OPB01, UBC 407 e UBC 412), os quais produziram um total de 199 perfis. Destes, apenas 12 foram monomórficos e os demais, 187 (93,97\%), foram polimórficos. Alguns produtos polimórficos são apresentados na Figura 1 . O número médio de polimorfismos obtido por marcador foi de 15,58. Entre os 12 "primers" utilizados registrou-se a presença de 45 perfis únicos, sendo que Mirabolano 29C apresentou o maior número de bandas exclusivas (17 no total). Todos os marcadores geraram bandas únicas para alguns dos genótipos, variando de 2 a 7 bandas para os marcadores OP B01 e OP $\mathrm{AD} 16$ e para os marcadores OPA18 e OPAC19, respectivamente. Aúnica exceção foi o marcador OPA07 que não produziu nenhuma banda característica.
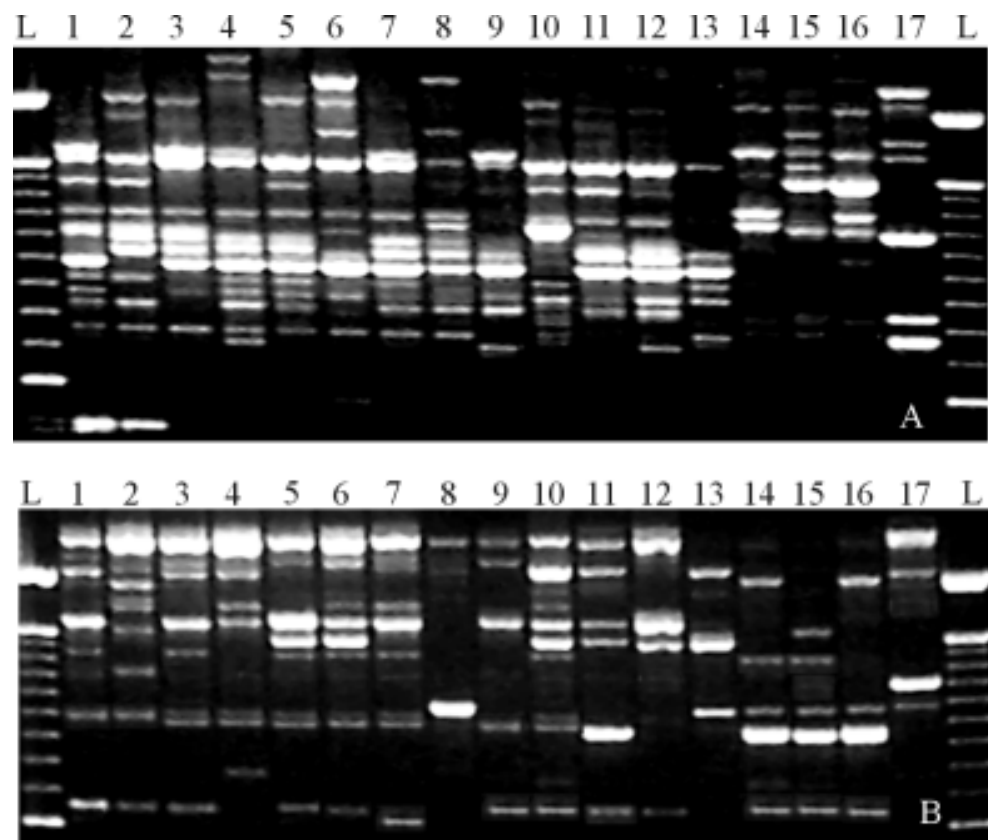

FIGURA 1 - Produtos da amplificação RAPD de 17 genótipos de ameixeira (Prunus sp.) gerados pelos “primers" OP A20 (A) e UBC 407 (B). L - Ladder 100pb, 1 a 17 corresponde ao nome das cultivares (verificar Tabela 1). FAEM-UFPel, Pelotas-RS, 2002.

Os marcadores utilizados permitiram diferenciar de maneira bastante segura cada genótipo de ameixeira analisado. Porém, Byrne \& Littleton (1988) verificaram que o uso de isoenzimas para o "fingerprinting" de 29 cultivares de ameixeira não permitiu identificar todos os genótipos, mas apenas $38 \%$ do total analisado.

Os resultados obtidos neste trabalho, com os marcadores RAPD, confirmam o alto grau de polimorfismo entre as diferentes espécies e cultivares de ameixeira, conforme verificado por Gregor et al. (1994), Ortiz et al. (1997) e Bianchi et al. (2002). Isso pode também ser atribuído à presença de cultivares de três espécies diferentes (Tabela 1), P. salicina, P. domestica e P. cerasifera (Mirabolano 29C), esta última incluída no conjunto de genótipos para verificar o potencial de uso da técnica RAPD em separar cultivares de diferentes espécies do mesmo gênero.

Considerando somente os perfis eletroforéticos das ameixeiras japonesas também se obteve alto polimorfismo, com um total de 150 bandas, destas, 134 (89,33\%) foram polimórficas e 16 (10,67\%) monomórficas. 
Em trabalho conduzido por Bianchi et al. (2002), as cultivares Santa Rosa, Letícia, Santa Rita, Pluma 7, América e Reubennel foram analisadas com marcadores moleculares SSR e AFLP e com uma única combinação de "primers" AFLP foi suficiente identificar as seis cultivares como $P$. salicina, o mesmo aconteceu quando utilizado o marcador SSR UDP96-019. Os resultados obtidos por estes autores estão em concordância com aqueles obtidos neste trabalho, verificando-se que o agrupamento destas seis cultivares ocorreu de maneira similar ao obtido com os marcadores AFLP eSSR.

O uso de marcadores RAPD permitiu uma clara separação das 3 espécies de ameixeira analisadas (Figura 2). Com o uso de 12 marcadores RAPD, a maior similaridade genética foi observada entre as cultivares de Prunus salicina, Irati e Amarelinha (83.06\%), seguido das cultivares de P. doméstica, Stanley e D’Agen (81,89\%).

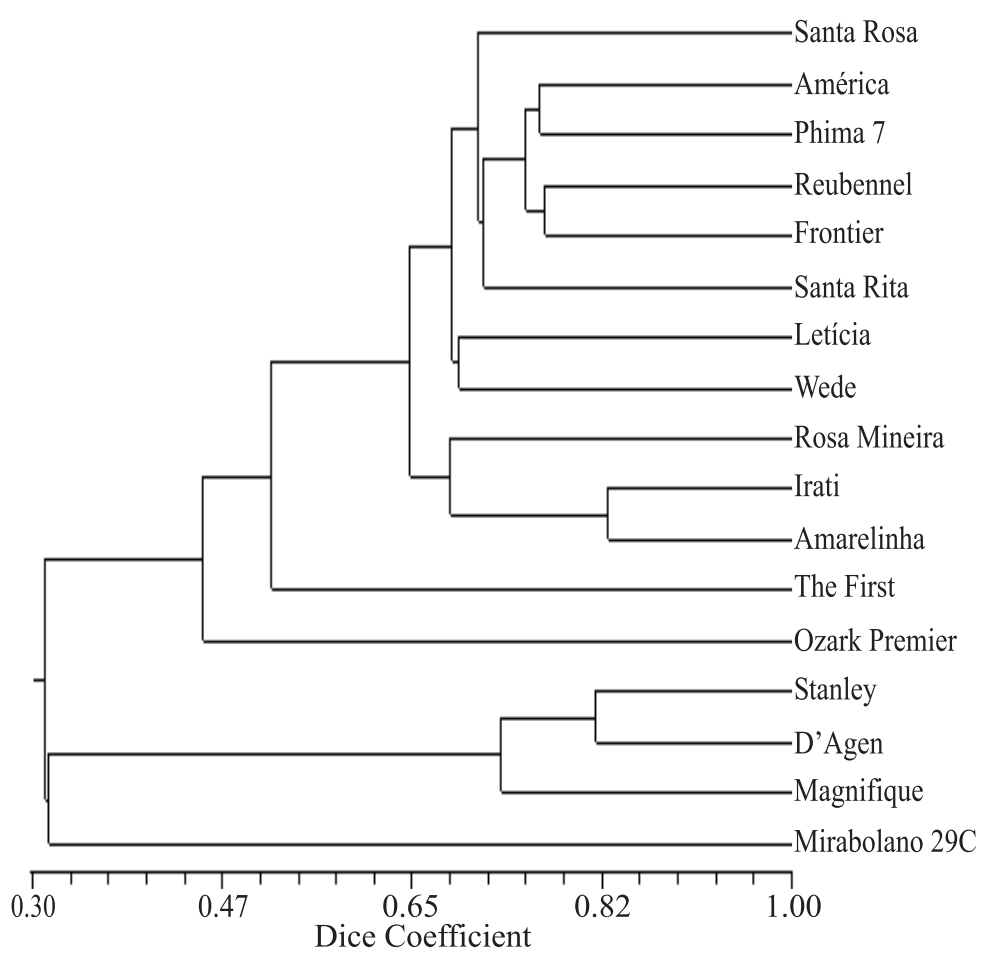

FIGURA 2 - Dendrograma de similaridade genética (UPGMA) de 17 genótipos de ameixeira (Prunus sp.), calculado com o Coeficiente Dice, para os dados obtidos com marcadores RAPD. FAEM-UFPel, Pelotas-RS, 2002.

No grupo da espécie P. salicina (Figura 2), verifica-se que as cultivares The First e Ozark Premier apresentam-se com maior distância genética em relação às outras cultivares desta espécie, a qual pode ser atribuída a possível contribuição de outras espécies, como P. domestica e P. cerasifera, na constituição genética destas cultivares. O caráter híbrido da ameixeira é confirmado com base na constituição genética da cultivar Ozark Premier (Burbank x Methley) 3/4 de P. salicina $+1 / 4$ de P. cerasifera (Byrne \& Littleton, 1988). Ortiz et al. (1997) também atribuem esta alta variabilidade genética observada entre cultivares de ameixeira a parcial auto-incompatibilidade que existe entre os diferentes genótipos.

As demais cultivares de P. salicina, pela distribuição no dendrograma, possivelmente possuem na constituição genética contribuição, principalmente, de P. salicina, P. americana e P. simonii, conforme relatado por Byrne \& Littleton (1988), para as cultivares Santa Rosa, Frontier e Wade.

As cultivares de P. domestica ficaram em um grupo intermediário no dendrograma, tendo Mirabolano 29C separado de todos os demais genótipos (Figura 2). Esse dado leva a interpretar que P. cerasifera é mais próxima geneticamente de P. domestica que de P. salicina. De acordo com Watkins, 1976 apud Bellini et al. (1998), isso ocorre devido a P. cerasifera ter o centro de origem geográfica próximo do centro de origem de P. domestica (Leste Europeu). Por outro lado, Reynders \& Salesses (1991) sugerem que as ameixeiras hexaplóides (P. domestica) tenham sido originadas de formas poliplóides de P. cerasifera. De qualquer forma, ambas teorias confirmam a existência de parentesco entre estas duas espécies.

\section{CONCLUSÕES}

A caracterização molecular de genótipos de ameixeira, analisados neste trabalho, pode ser realizada de forma eficiente através dos marcadores RAPD. Resultados significativos foram obtidos com estes marcadores, permitindo estimar a variabilidade genética entre genótipos de ameixeira e diferenciação das espécies.

\section{REFERÊNCIASBIBLIOGRAFICAS}

BIANCHI, V.J.; VENTURI, S.; FACHINELLO, J.C.; TARTARINI, S.; SANSAVINI, S. I marcatori AFLPe SSR, risolutivi nella identificazione genética delle varietá di susino. Frutticoltura, Bologna, n. 4, p. 83-87, 2002.

BELLINI, E.; GIORDANI, E.; NENCETTI, V.; PAFFETTI, D. Genetic relationships in Japanese plum cultivars by molecular markers. Acta Horticulturae, Wageningen, v. 478, p. 53-6, 1998.

BYRNE, D.H.; LITTLETON, T.G. Electrophoretic characterization of diploid plums of southeastern United States. Journal American Society Horticulturae Science, Alexandria, v. 113, p. 918-924. 1988.

CASSAS, A.M.; IGARTUA, E.; BALAGUER, G.; MORENO, M.A. Genetic diversity of Prunus rootstocks analyzed by RAPD markers. Euphytica, Netherlands, n. 110, p. 139-149, 1999.

GOULAO, L.; MONTE-CORVO, L.; OLIVEIRA, C.M. Phenetic characterization of plum cultivars by high multiplex ratio markers: Amplified fragment length polymorphisms and inter-simple sequence repeats. Journal American Society Horticulturae Science, Alexandria, v. 126, n. 1, p. 72-77. 2001.

GRANDO, M.S.; VINDIAMIN, M.E. Marcatori RAPD in germoplasma di Prunus domestica: verifica della presunta similarità genetica delle cultivar Pozegaca, Hauszetsche e Dro. Italus Hortus, Roma, v. 3, n. 2 , p. 45-48. 1996.

GREGOR, G.; HARTMANN, W.; STOSSER, R. Cultivar identification in Prunus domestica using random amplified polymorphic DNA markers. Acta Horticulturae, Wageningen, v. 359, p. 33-40. 1994.

KOLLER, B.; LEHMANN, J.; McDERMOTT, J.M.; GESSLER, C. Identification of apple cultivars using RAPD markers. Theoretical and Applied Genetics, Berlin, v.85, p.901-904, 1993.

MONTE-CORVO, L.; CABRITA, L.; OLIVEIRA, C.M.; LEITÃO, J.Assessment of genetic relationships among Pyus species and cultivars using AFLP and RAPD markers. Genetic Resourses and Crop Evolution, Dorchecht, v. 47, p. 257-265, 2000.

MULCAHY, D.L.; CRESTI, M.; SANSAVINI, S.; DOUGLAS, G.C.; LINSKENS, H.F.; BERGAMINI MULCAHY, G.; VIGNANI, R.; PANCALDI, M. The use of random amplified polymorphic DNAs to fingerprint apple genotypes. Scientia Horticulturae, Amsterdam, v. 54, p. 89-96, 1993.

ORTIZ, A.; RENAUD, R.; CALZADA, I.; RITTER, E. Analysis of plum cultivars with RAPD markers. Journal of Horticultural Science, Ashford, kent, v. 72, p. 1-9. 1997.

PANCALDI, M.; VINATZER, B.; SANSAVINI, S. Utilità delle analisi molecolari per risolvere li sinonimie nel susino. Frutticoltura, Bologna, n. 7/8, p. 67-72. 2000.

REYNDERS, S.; SALESSES, G. Study on the relationships within the subgenus Prunophora. Restriction maps of the ribosomal genes in $P$. cerasifera and $P$ spinosa. Acta Horticulturae, Wageningen, n. 283, p. 27-27, 1991.

ROHLF, F.J. NTSYS.PC. Numerical taxonomy and multivariate analysis system. Version 1.8. Exeter Publications, Setauket, New York, 1993.

SANSAVINI, S. Biotecnologie fruticole: le nuove frontiere delle ricerche per il miglioramento genetico e la propagazione delle piante da frutto. Frutticoltura, Bologna, n. 5, p. 75-81. 1998.

SHIMADA, T.; HAYAMA, H.; HAJI, T.; YAMAGUCHI, M.; YOSHIDA, $M$. Genetic diversity of plums characterized by random amplified polymorphic DNA(RAPD) analysis. Euphytica, Dorchecht, v. 109, p. 143147.1999. 